\title{
Do thromboembolic events increase in the emergency department during COVID-19 era?
}

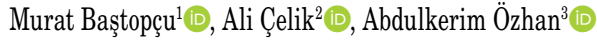 \\ ${ }^{1}$ Department of Cardiovascular Surgery, Tatvan State Hospital, Bitlis, Turkey \\ ${ }^{2}$ Department of Emergency Medicine, Recep Tayyip Erdoğan University Training and Research Hospital, Rize, Turkey \\ ${ }^{3}$ Department of Cardiovascular Surgery, Kütahya Evliya Çelebi Training and Research Hospital, Kütahya, Turkey
}

Received: June 25, 2020 Accepted: July 18, 2020 Published online: July 28, 2020

\section{ABSTRACT}

Objectives: In this study, we aimed to investigate whether thromboembolic events increased in the emergency department (ED) setting due to asymptomatic carriers.

Patients and methods: This single-center, retrospective study included a total of 40,633 patients who were admitted to ED after the first case of COVID-19 in Turkey, between 11 March 2020 and 26 May 2020 and the corresponding dates in 2019. The number of patients and demographic and clinical characteristics were compared between the two years for cardiovascular surgery (CVS)-related venous and arterial thromboembolism events.

Results: Emergency department admissions requiring CVS consultations decreased by $41.6 \%$ from 77 patients in 2019 to 45 patients in 2020. Total CVS consultations over the 11-week period per 1,000 ED admissions increased from 2.9 to 3.2. The number of deep vein thrombosis decreased from 14 to 9 during pandemic, while there was no significant difference in weekly cases of venous thrombosis. The number of arterial thromboembolism cases was 11 in 2019 and six in 2020. Weekly arterial thromboembolism admissions were not significantly different between the two years.

Conclusion: Our study results showed that the rate of thromboembolic events did not increase in the general population admitted to the ED during the first 11 weeks of the COVID-19 pandemic in Rize province of Turkey.

Keywords: Arterial thromboembolism, COVID-19, deep vein thrombosis, SARS-CoV2, thrombosis, venous thromboembolism.

Since its emergence in December 2019 in Wuhan, China, the novel coronavirus 2019 (severe acute respiratory syndrome coronavirus-2 [SARS-Cov-2]) has spread worldwide causing a pandemic. As of June $1^{\text {st }}$, more than six million cases were diagnosed across the world. ${ }^{[1]}$ Mainly presenting with pneumonia of varying severity, clinicians were challenged with the wide range of clinical spectrum with which the COVID-19 is associated, pursuing to battle the public health emergency and understand it at the same time. Typical symptomatology of COVID-19 includes fever, cough, and shortness of breath. ${ }^{[2,3]}$ Limiting diagnosis and screening to these symptoms overlooks many cases with COVID-19 as an estimated 30 to $50 \%$ of all infected individuals transmitted the disease with no or atypical symptoms, including but not limited to gastrointestinal, neurological, and cardiovascular complaints. ${ }^{[4]}$

Recent observations have revealed that, in hospitalized patients with COVID-19 infection, venous and arterial thrombotic events are frequent, even in low-risk and anticoagulated patients. ${ }^{[5-7]}$ Deep vein thrombosis and pulmonary embolism, coronary and limb ischemia complicate the course of the disease. Both COVID-19 infection itself, the inflammatory response in severe cases, and the drug-drug interactions in the admitted patients with underlying risk factors can predispose to thrombosis. ${ }^{[8]}$ Due to this predisposition and the risk of drug-drug interactions, low-molecular-weight heparin or unfractionated heparin is recommended for prophylaxis in all patients without a contraindication for COVID-19..$^{[9]}$ However, it is still unclear whether COVID-19 itself directly plays a role in thromboembolism or the immune system response to the infection with varying

Corresponding author: Murat Baştopçu, MD. Tatvan Devlet Hastanesi Kalp ve Damar Cerrahisi Kliniği, 13200 Tatvan, Bitlis, Turkey.

Tel: +90 434 - 8276325 e-mail: muratbastop@gmail.com

\section{Citation:}

Baştopçu M, Çelik A, Özhan A. Do thromboembolic events increase in the emergency department during COVID-19 era?. Cardiovasc Surg Int 2020;7(2):84-89. 
scale has thrombotic effects, and patients with no evident respiratory symptoms may be affected by the prothrombotic changes.

In the present study, we aimed to investigate whether thromboembolic events increased in the emergency department (ED) setting due to asymptomatic carriers in the COVID-19 era.

\section{PATIENTS AND METHODS}

This single-center, retrospective study included a total of 40,633 patients who were admitted to ED after the first case of COVID-19 in Turkey, between 11 March 2020 and 26 May 2020 and the corresponding dates in 2019 in Rize province. All patients with ED admissions throughout the study were included. Pediatric patients with $<18$ years of age were excluded. Patients consulted to the cardiovascular surgery (CVS) department for any cause were classified as CVSrelated admissions. Data including demographic and clinical characteristics of the patients, diagnoses and comorbidities were recorded. A written informed consent was obtained from each patient. The study protocol was approved by the Recep Tayyip Erdoğan University Training and Research Hospital Ethics Committee and the Republic of Turkey, Ministry of Health. The study was conducted in accordance with the principles of the Declaration of Helsinki.

All lower and upper extremity deep vein thrombosis, and central venous thrombosis were classified as venous thrombosis. Upper and lower limb arterial thromboembolisms (ATEs) were classified as arterial thrombosis. Cerebral venous thrombosis, stroke, or acute coronary syndrome cases were excluded, as they were not consulted to the CVS department. Aortic dissections included all types of acute aortic dissections, and aortic aneurysms included all aortic aneurysms of any location with or without rupture. Vascular traumas included isolated vascular injuries or multi-trauma with vascular injuries.

\section{Statistical analysis}

Statistical analysis was performed using the IBM SPSS version 25.0 software (IBM Corp., Armonk, NY, USA). Continuous variables were expressed in mean \pm standard deviation (SD) or median (min-max), while categorical variables were presented in number and percentage. The chi-square test was used to analyze categorical variables, while the Student's t-test was used to analyze normally distributed continuous

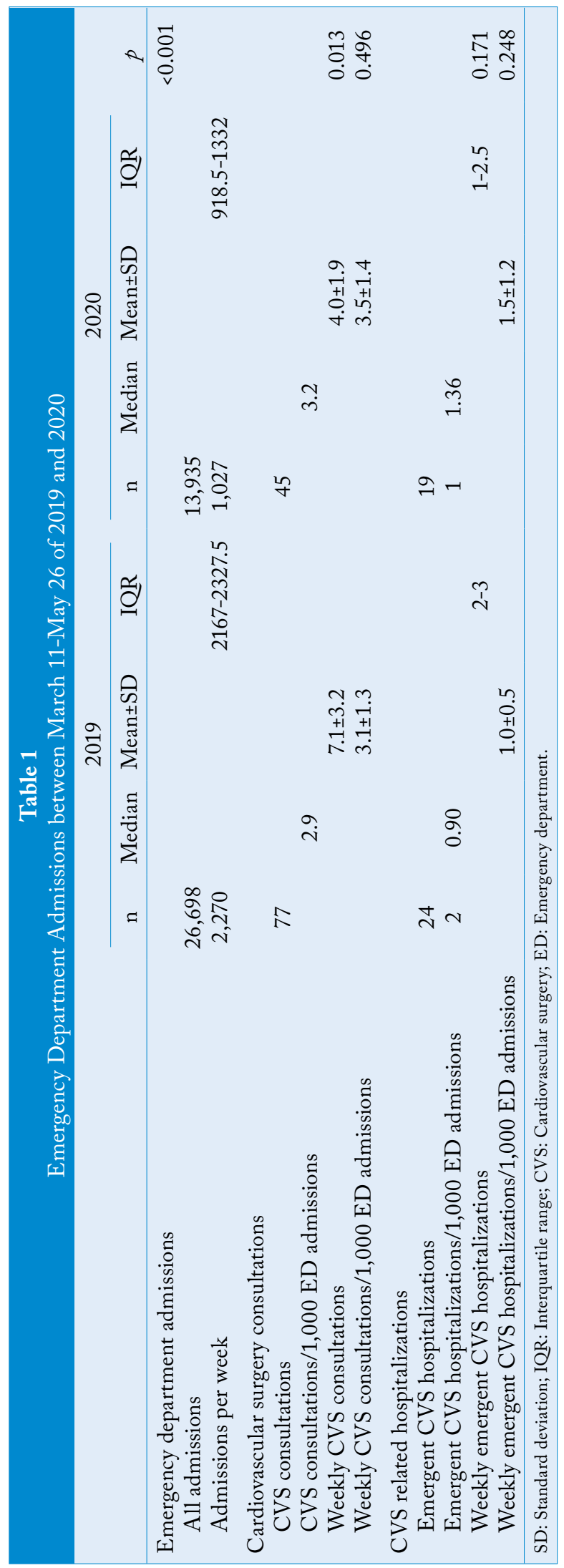




\begin{tabular}{|c|c|c|c|c|c|c|c|}
\hline \multicolumn{8}{|c|}{$\begin{array}{c}\text { Table } 2 \\
\text { Presenting Diagnoses of Cardiovascular Surgery-related Emergency Department Admissions }\end{array}$} \\
\hline & \multicolumn{3}{|c|}{2019} & \multicolumn{3}{|c|}{2020} & \multirow[b]{2}{*}{$p$} \\
\hline & $\mathrm{n}$ & Median & IQR & $\mathrm{n}$ & Median & IQR & \\
\hline \multicolumn{8}{|l|}{ Emergency CVS diagnoses } \\
\hline Venous thrombosis & 14 & & & 9 & & & \\
\hline Venous thrombosis per week & & 1 & $0-2$ & & 1 & $0-1.5$ & 0.519 \\
\hline Arterial thromboembolism & 11 & & & 6 & & & \\
\hline Arterial thromboembolism per week & & 1 & $0.5-1.5$ & & 0 & $0-1$ & 0.193 \\
\hline Acute aortic dissections & 3 & & & 2 & & & \\
\hline Aortic aneurysm & 5 & & & 8 & & & \\
\hline Vascular trauma & 25 & & & 13 & & & \\
\hline
\end{tabular}

variables. Non-normally distributed variables were compared using the Mann-Whitney U test. A $p$ value of $<0.05$ was considered statistically significant.

\section{RESULTS}

Throughout the study period, there were 26,698 ED admissions in 2019 and 13,935 ED admissions in 2020. Details on ED admissions are presented in Table 1. Considering all ED admissions per week, there was a decrease in weekly ED admissions in 2020 (1,027 vs. $2,270, \mathrm{p}<0.001)$. The ED admissions requiring CVS consultations decreased by $41.6 \%$ from 77 patients in 2019 to 45 patients in 2020 . Total CVS consultations per 1,000 ED admissions increased from 2.9 to 3.2. Similarly, the mean total CVS consultations per week decreased ( 7.09 vs. $4.00, \mathrm{p}=0.013$ ), although this decrease was likely caused by the drop in total admissions as the mean total CVS-related admissions per 1,000 ED admissions increased (3.08 vs. 3.47, $\mathrm{p}=0.496$ ), indicating no statistical significance.

In addition, CVS-related hospitalizations decreased from 24 patients in 2019 to 19 patients in 2020. In contrast, the ratio of CVS-related hospitalizations per $1,000 \mathrm{ED}$ admissions increased from 0.90 in 2019 to 1.36 in 2020. Weekly CVS-related hospitalizations per 1,000 ED admissions increased from 1.00 to 1.46, indicating no statistical significance.

All CVS admissions were classified according to the presenting pathology (Table 2). Total cases of deep vein thrombosis decreased from 14 to 9 during the study, and there was no significant difference in weekly cases of venous thrombosis. Concerning
ATE, the number of cases was 11 in 2019, whereas six patients had ATE during the same period in 2020. Weekly arterial thrombosis admissions were not significantly different between 2019 and 2020.

All ED admissions in 2019 and 2020 were compared for comorbidities (Table 3). Among all patients consulted to CVS, there were fewer cases with chronic renal failure in $2020(2.2 \%$ vs. $15.6 \%$, $\mathrm{p}=0.030$ ), while there were no significant differences in other comorbidities. Venous thrombosis patients and ATE patients in 2019 and 2020 showed no significant difference for documented comorbidities. In total, there were three cases of aortic dissection in 2019 and two cases in 2020. The number of patients consulted for aortic aneurysm with or without rupture was five in 2019 and eight in 2020. A major cause of CVS consultations was vascular trauma in 25 cases in 2019 and in 13 cases in 2020.

\section{DISCUSSION}

In this single-center study, the rate of thrombotic diseases did not increase in the general population as evidenced by ED admissions during the COVID-19 era, compared to the same period in the previous year. In addition, there was no significant difference in the number of venous and arterial thrombotic cases between the two years.

Our hospital serves a city of approximately 350,000 population. Within one week of the first COVID-19 case in Turkey, patients suspected of COVID-19 infections were diagnosed in the study hospital. The ED was arranged in accordance with the Republic of 


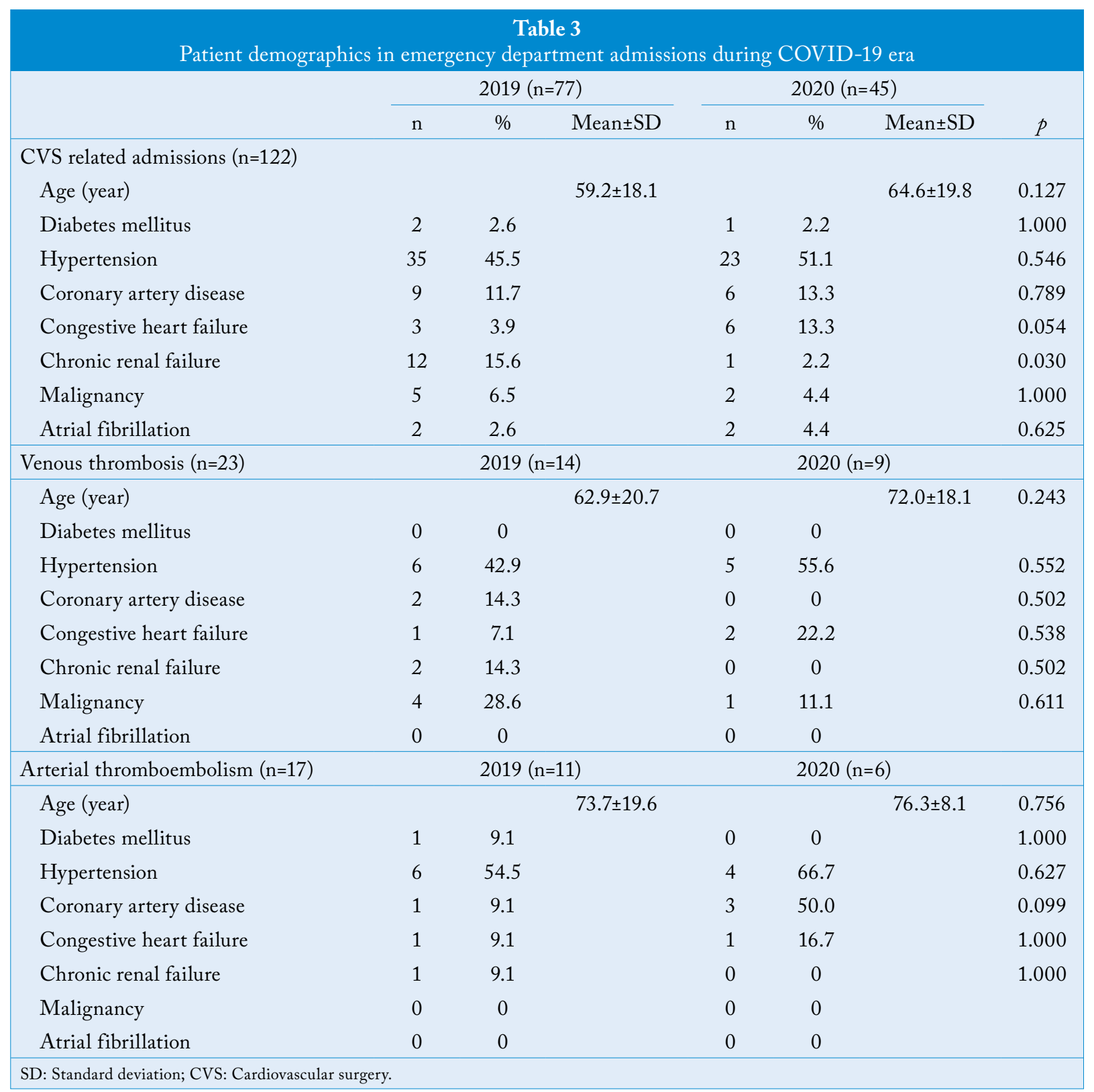

Turkey, Ministry of Health guidelines, with suspected COVID-19 patients examined in an area separate from the other ED admissions. If a patient carried the COVID-19, but did not show any infectious or respiratory symptoms, they would be unaware of their infection and might have presented with other atypical symptoms, and such cases would not be initially suspected of COVID-19. There are reported cases of COVID-19 presenting with venous thrombotic events or stroke and subsequently being diagnosed with COVID-19. ${ }^{[10,11]}$ We believe that such cases would result in more ED admissions for thrombotic events during the pandemic, but failed to show an increase in thrombotic events in the ED of the study center.

Most reports of venous or arterial thrombosis in COVID-19 patients are based on patients with a severe course of infection and in the intensive care unit (ICU) setting. ${ }^{[12-15]}$ However, not all thrombotic events related to COVID-19 were associated with ICU requirement, and severe arterial or venous thromboembolism (VTE) were detected in patients with milder symptoms ${ }^{[5,6,16-18]}$ or even as presenting 
symptoms. ${ }^{[10,19]}$ It is likely that the risk of thrombosis is high in severe cases and low in mild or asymptomatic cases. As the patients with CVS-related admissions did not present with typical symptoms of COVID-19 and they were not tested for the novel coronavirus, the number of COVID-19 infections among this patient group may be undetermined.

There was a drop in the absolute number of total ER admissions during the COVID-19 era. Selfisolation, stay-at-home orders by the government, or fear of contracting the virus at the hospital may have prevented patients from seeking emergency care. Despite the drop in total ED admissions, there was an insignificant increase in the number of CVS-related admissions. The demographic factors were overall not different between the two years, except for chronic renal failure which was less frequent in 2020; therefore, the lack of increase in thrombotic events cannot be attributed to the differences in comorbidities. It is possible that patients with more severe symptomatology opted to seek emergency care during the pandemic and patients with mild symptoms of any cause did not admit to the ED. Due to similar reasons, some minor VTE or ATE may not have reached the hospital due to fears of leaving the house or waiting in the hospital. Italy is one of the European countries with the largest impact of COVID-19 and the association with thrombosis notwithstanding, admissions for acute coronary syndrome reduced in all parts of the country. ${ }^{[20]}$ Likewise, recorded cases of strokes diminished in a neurological center in Italy during the March. ${ }^{[21]}$ The prominent explanation in both cases in Italy and our case is the fear of contact with the virus, while seeking medical attention for other causes. It is a point of concern that some patients with minor thrombotic disease, such as a distal deep vein thrombosis or a mild new-onset claudication may wait, until the pandemic recedes to seek medical attention and their disease may complicate the course of treatment.

The main limitation of this study is its retrospective design and insufficient data collection. Another limitation is that our study was conducted in a single state hospital serving a city of a relatively small population. Although the study hospital is the largest in the city, there could be patients admitted to smaller distant hospitals and, therefore, not included in the study. Thus, further studies from larger cities or multi-center studies are needed to confirm our results.
In conclusion, the rate of thromboembolic events did not increase in the general population admitted to the ED during the first 11 weeks of the COVID19 pandemic in Rize province of Turkey. However, further studies from other centers are needed to determine whether thromboembolic events tend to increase due to mild or asymptomatic cases of COVID-19.

\section{Declaration of conflicting interests}

The authors declared no conflicts of interest with respect to the authorship and/or publication of this article.

\section{Funding}

The authors received no financial support for the research and/or authorship of this article.

\section{REFERENCES}

1. World Health Organization. Coronavirus disease (COVID-2019) situation reports. [Internet]. World Heal. Organ. 2020. p. 2633. Available at: https://www.who.int/ emergencies/diseases/novel-coronavirus-2019/situationreports

2. Vetter $\mathrm{P}, \mathrm{Vu} \mathrm{DL}$, L'Huillier AG, Schibler M, Kaiser L, Jacquerioz F. Clinical features of covid-19. BMJ 2020;369:m1470.

3. Göçer H, Durukan AB. ACE-gene polymorphism, particularly " $\mathrm{D} / \mathrm{I}$ ", may play a role in the occurrence of COVID-19 pneumonia in hypertensive elderly patients. Cardiovasc Surg Int 2020;7:39.

4. Gao Z, Xu Y, Sun C, Wang X, Guo Y, Qiu S, et al. A Systematic Review of Asymptomatic Infections with COVID-19. J Microbiol Immunol Infect. 2020. [Online ahead of print]

5. Grandmaison G, Andrey A, Périard D, Engelberger RP, Carrel G, Doll S, et al. Systematic Screening for Venous Thromboembolic Events in COVID-19 Pneumonia. TH Open 2020;4:e113-e5.

6. Lodigiani C, Iapichino $G$, Carenzo L, Cecconi M, Ferrazzi P, Sebastian T, et al. Venous and arterial thromboembolic complications in COVID-19 patients admitted to an academic hospital in Milan, Italy. Thromb Res 2020;191:9-14.

7. Zhang L, Feng X, Zhang D, Jiang C, Mei H, Wang J, et al. Deep vein thrombosis in hospitalized patients with COVID-19 in Wuhan, China: Prevalence, risk factors, and outcome. Circulation 2020;142:114-28.

8. Bikdeli B, Madhavan MV, Jimenez D, Chuich T, Dreyfus I, Driggin E, et al. COVID-19 and Thrombotic or Thromboembolic Disease: Implications for Prevention, Antithrombotic Therapy, and Follow-Up: JACC State-ofthe-Art Review. J Am Coll Cardiol 2020;75:2950-73.

9. Akay T. Perioperative planning in the COVID-19 pandemic: Vascular issues. Turk Gogus Kalp Dama 2020;28:244-6. 
10. Davoodi L, Jafarpour H, Taghavi M, Razavi A. COVID-19 Presented With Deep Vein Thrombosis: An Unusual Presenting. J Investig Med High Impact Case Rep 2020;8:2324709620931239.

11. Fara MG, Stein LK, Skliut M, Morgello S, Fifi JT, Dhamoon MS. Macrothrombosis and stroke in patients with mild Covid-19 infection. J Thromb Haemost 2020. [Online ahead of print]

12. Klok FA, Kruip MJHA, van der Meer NJM, Arbous MS, Gommers DAMPJ, Kant KM, et al. Incidence of thrombotic complications in critically ill ICU patients with COVID-19. Thromb Res 2020;191:145-7.

13. Ren B, Yan F, Deng Z, Zhang S, Xiao L, Wu M, et al. Extremely high incidence of lower extremity deep venous thrombosis in 48 patients with severe COVID-19 in Wuhan. Circulation 2020;142:181-3.

14. Nahum J, Morichau-Beauchant T, Daviaud F, Echegut P, Fichet J, Maillet JM, et al. Venous thrombosis among critically Ill patients with coronavirus disease 2019 (COVID-19). JAMA Netw Open 2020;3:e2010478.

15. Llitjos JF, Leclerc M, Chochois C, Monsallier JM, Ramakers M, Auvray M, et al. High incidence of venous thromboembolic events in anticoagulated severe COVID19 patients. J Thromb Haemost 2020;18:1743-6.
16. Kashi M, Jacquin A, Dakhil B, Zaimi R, Mahé E, Tella E, et al. Severe arterial thrombosis associated with Covid-19 infection. Thromb Res 2020;192:75-7.

17. Stoneham SM, Milne KM, Nuttall E, Frew GH, Sturrock BR, Sivaloganathan $\mathrm{H}$, et al. Thrombotic risk in COVID19: a case series and case-control study. Clin Med (Lond) 2020;20:e76-e81.

18. Gomez-Arbelaez D, Ibarra-Sanchez G, Garcia-Gutierrez A, Comanges-Yeboles A, Ansuategui-Vicente M, GonzalezFajardo JA. COVID-19-Related Aortic Thrombosis: A Report of Four Cases. Ann Vasc Surg 2020. [Online ahead of print]

19. Prieto-Lobato A, Ramos-Martínez R, Vallejo-Calcerrada N, Corbí-Pascual M, Córdoba-Soriano JG. WITHDRAWN:A Case Series of Stent Thrombosis During the COVID-19 Pandemic. JACC Case Rep 2020. [Online ahead of print]

20. De Rosa S, Spaccarotella C, Basso C, Calabrò MP, Curcio A, Filardi PP, et al. Reduction of hospitalizations for myocardial infarction in Italy in the COVID-19 era. Eur Heart J 2020;41:2083-8.

21. Morelli N, Rota E, Terracciano C, Immovilli P, Spallazzi M, Colombi D, et al. The Baffling Case of Ischemic Stroke Disappearance from the Casualty Department in the COVID-19 Era. Eur Neurol 2020;83:213-5. 